Article

\title{
Synergistic Antifungal Activity of Chitosan with Fluconazole against Candida albicans, Candida tropicalis, and Fluconazole-Resistant Strains
}

\author{
Wei-Hsuan Lo, Fu-Sheng Deng, Chih-Jung Chang and Ching-Hsuan Lin * \\ Department of Biochemical Science and Technology, College of Life Science, National Taiwan University, \\ Taipei 10617, Taiwan; r07b22008@ntu.edu.tw (W.-H.L.); d04b22004@ntu.edu.tw (F.-S.D.); \\ r02b22003@ntu.edu.tw (C.-J.C.) \\ * Correspondence: chinghsuanlin@ntu.edu.tw; Tel.: +886-233-664-449
}

Academic Editor: Mohamed Samir Mohyeldin

Received: 6 October 2020; Accepted: 30 October 2020; Published: 3 November 2020

\begin{abstract}
Background: Few antifungal drugs are currently available, and drug-resistant strains have rapidly emerged. Thus, the aim of this study is to evaluate the effectiveness of the antifungal activity from a combinational treatment of chitosan with a clinical antifungal drug on Candida albicans and Candida tropicalis. (2) Methods: Minimum inhibitory concentration (MIC) tests, checkerboard assays, and disc assays were employed to determine the inhibitory effect of chitosan with or without other antifungal drugs on C. albicans and C. tropicalis. (3) Results: Treatment with chitosan in combination with fluconazole showed a great synergistic fungicidal effect against $C$. albicans and C. tropicalis, but an indifferent effect on antifungal activity when challenged with chitosan-amphotericin $\mathrm{B}$ or chitosan-caspofungin simultaneously. Furthermore, the combination of chitosan and fluconazole was effective against drug-resistant strains. (4) Conclusions: These findings provide strong evidence that chitosan in combination with fluconazole is a promising therapy against two Candida species and its drug-resistant strains.
\end{abstract}

Keywords: Candida albicans; Candida tropicalis; chitosan; fluconazole; synergistic effect

\section{Introduction}

The incidence of fungal infections has increased significantly in recent decades. Current epidemiological surveys have reported that Candida species are the leading causes of nosocomial bloodstream infections, which can lead to high mortality rates in at-risk populations [1,2]. However, the issues of currently available antifungal drugs include undesirable side effects and therapeutic failure of the antifungal treatment against drug-resistant strains.

Chitosan, poly-( $\beta-1 \rightarrow 4)-2$-amino-2-deoxy-D-glucopyranose, is a linear polysaccharide produced by the partial deacetylation of chitin [3-8]. Because of its biocompatible, biodegradable, and nontoxic properties, chitosan has been used in many biomedical and therapeutic applications [3-8]. For example, halloysite nanotubes coated by chitosan and chitosan nanoparticles have been intensively investigated, and the findings demonstrated that chitosan is a suitable drug delivery system for in vitro and in vivo treatment, thus indicating that chitosan could have promising medicinal applications [9-13]. Additionally, chitosan shows considerable antimicrobial activity against a variety of bacteria and fungi [5-7,14-25]. However, the mechanisms underlying its antimicrobial activity remain largely unclear. Chitosan has been suggested to exhibit polycationic polymers when the environmental $\mathrm{pH}$ is below $6.5[17,21,23]$, which leads to interactions with the negatively charged bacterial or fungal cell surface, thereby causing an inhibitory effect [6-8,22-24].

Combination therapy is generally effective against pathogenic microbes that show drug resistance [26-29]. The use of chitosan as a fluconazole delivery system or a polymer film containing 
clinical drugs has been developed to treat infectious candidiasis [30,31]. These studies showed that the advantages of chitosan-based scaffold materials include the control of drug release and the maintenance of a high local concentration of the antibacterial or antifungal drug over a long period of time $[30,31]$. However, the antifungal efficacy of chitosan in combination with clinical antifungal drugs has been quantified, and the results presented contradictory conclusions [14,32]. Low-molecular-weight chitosan (LMWC; $70 \mathrm{kDa} ;>75 \%$ deacetylation) exhibited promising anti-Candida effects at $\mathrm{pH} 4.0$, whereas the combination of LMWC and fluconazole did not have a synergistic effect at neutral pH [14]. Interestingly, C32, a $15 \mathrm{kDa}$ chitooligosaccharide (CHOS) with $0.15 \mathrm{~F}_{\mathrm{A}}$ (fraction of acetylation), showed great synergistic effects against Candida albicans, Candida guilliermondii, and Candida lusitaniae, but had an indifferent effect against Candida tropicalis when in combination with different antifungals [32]. These data suggest that the molecular weight (MW) and degree of deacetylation of chitosan might result in different outcomes. Nevertheless, previous studies have mainly focused on one chitosan with a low MW or oligo form. Chitosan with different MWs and degrees of deacetylation against C. albicans and C. tropicalis as well as drug-resistant strains have never been studied.

In this study, six commercial chitosans with distinct MWs and degrees of deacetylation were analyzed to evaluate their antifungal activity and synergistic effects with antifungal drugs against C. albicans SC5314 [33], C. tropicalis MYA3404 [33], and drug-resistant strains because C. albicans and C. tropicalis are the most isolated fungal pathogens in tropical and subtropical regions, including Taiwan [34-36]. In this study, we first determined the minimum inhibitory concentration (MIC) of chitosan, fluconazole, amphotericin B, and caspofungin. The fractional inhibitory concentration $\left(\right.$ FIC $\left._{\text {index }}\right)$ determined by checkerboard assays further showed great synergistic antifungal activity against two Candida species and the drug-resistant strains in liquid medium after treatment with chitosan-fluconazole, but not chitosan-amphotericin B or chitosan-caspofungin. Together, our findings will reveal new potential and promising therapeutic methods or medical applications to control Candida infections.

\section{Results}

\subsection{Susceptibility of C. albicans SC5314 to Antifungal Drugs and Chitosan with Different MWs}

Many review articles have implied that the major mechanism of chitosan against microorganisms is the targeting of the cell wall and cell membrane $[4-7,17,19,22-24,31]$. Therefore, three classes of antifungal drugs, namely, fluconazole, amphotericin B, and caspofungin, were selected for this study. The in vitro antifungal activities of fluconazole, amphotericin B, caspofungin, and chitosan with different properties were analyzed against C. albicans SC5314. As shown in Table 1, the commercial chitosans alone did not exhibit great antifungal activity because the MICs ranged from $>2000 \mu \mathrm{g} / \mathrm{mL}$ (3 kDa chitosan oligomer and 20-35 kDa chitosan) to $1000 \mu \mathrm{g} / \mathrm{mL}$ (15 kDa and MMW chitosans), thus corroborating a previous report [32]. Notably, the MIC of HMW chitosan could not be determined because it can only dissolve at higher concentrations of acetic acid (giving a $\mathrm{pH}<4.5$ ), and the low $\mathrm{pH}$ profoundly inhibited the growth of C. albicans (Table 1). Thus, HMW chitosan was not analyzed in the following experiments. Similar to previous reports [37], C. albicans SC5314 was highly susceptible to fluconazole (MIC: $0.125 \mu \mathrm{g} / \mathrm{mL}$ ), amphotericin B (MIC: $1.0 \mu \mathrm{g} / \mathrm{mL})$, and caspofungin $(0.25 \mu \mathrm{g} / \mathrm{mL})$.

\subsection{Chitosan Can Enhance the Antifungal Activity of Fluconazole}

The susceptibility range of C. albicans was evaluated using three antifungal drugs (fluconazole, amphotericin B, and caspofungin) with chitosans presenting different properties (except HMW chitosan). The combination of the abovementioned antifungal drugs and chitosan showed synergistic action with fluconazole and exhibited a remarkable inhibitory effect on C. albicans SC5314. The FIC index of each sample in the chitosan-fluconazole checkerboard assay was $<0.5$ (Table 2). However, chitosan in combination with amphotericin B or caspofungin showed an indifferent effect, with each FIC index $_{1}$ between 0.5 and 4.0 (Table 2). To obtain better visualization results, disk diffusion assays were utilized. 
We further demonstrated that the combined treatment of a particular chitosan with fluconazole exhibited great antifungal activity (Figure 1A); however, obvious inhibitory effects were not observed for the combinations of chitosan-amphotericin B (Figure 1B) and chitosan-caspofungin (Figure 1C). Notably, the $3 \mathrm{kDa}$ and MMW chitosans with fluconazole had no obvious synergistic antifungal effects on C. albicans SC5314 in the disk diffusion assays (Figure 1A). Turbid haloes were observed after treatment with fluconazole alone because fluconazole is a fungistatic antifungal drug rather than a fungicidal agent [38]. These data suggest that the synergistic effects against C. albicans SC5314 are profoundly affected by the assay that was performed (MIC tests in liquid medium versus disk diffusion assays on agar medium).

Table 1. Minimum inhibitory concentrations (MICs) of chitosans with different MWs and deacetylation degrees in combination with antifungal drugs against C. albicans SC5314.

\begin{tabular}{ccc}
\hline Chitosan or Drug & Strain & MIC $(\mu \mathrm{g} / \mathbf{m L})$ \\
\hline 3 kDa chitosan & C. albicans & $>2000$ \\
\hline$\sim 15$ kDa chitosan & C. albicans & 1000 \\
\hline $20-30$ kDa chitosan & C. albicans & $>2000$ \\
\hline LMW chitosan & C. albicans & 2000 \\
\hline MMW chitosan & C. albicans & 1000 \\
\hline HMW chitosan: & C. albicans & n.d. \\
\hline Fluconazole & C. albicans & 0.125 \\
\hline Amphotericin B & C. albicans & 1 \\
\hline Caspofungin & C. albicans & 0.25 \\
\hline
\end{tabular}

Table 2. Checkerboard assays of each chitosan in combination with an antifungal drug against $C$. albicans SC5314. FIC, fractional inhibitory concentration.

\begin{tabular}{ccc}
\hline Antifungal Drug & Chitosan & FIC $_{\text {index }}$ \\
\hline \multirow{3}{*}{ Fluconazole } & 3 kDa chitosan & $0.5 \pm 0.125$ \\
\cline { 2 - 3 } & $\sim 15 \mathrm{kDa}$ chitosan & $0.125 \pm 0.035$ \\
\cline { 2 - 3 } & 20-30 kDa chitosan & $0.113 \pm 0.038$ \\
\cline { 2 - 3 } & LMW chitosan & $0.118 \pm 0.043$ \\
\hline Amphotericin B & MMW chitosan & $0.041 \pm 0.021$ \\
\cline { 2 - 3 } & $\sim 15 \mathrm{kDa}$ chitosan & $1.75 \pm 0.25$ \\
\cline { 2 - 3 } & 20-30 kDa chitosan & $1.625 \pm 0.625$ \\
\cline { 2 - 3 } & LMW chitosan & $1.505 \pm 0.495$ \\
\cline { 2 - 3 } Caspofungin & MMW chitosan & $1.505 \pm 0.495$ \\
\cline { 2 - 3 } & 3 kDa chitosan & $2.515 \pm 1.485$ \\
\cline { 2 - 3 } & $\sim 15 \mathrm{kDa}$ chitosan & $1.078 \pm 0.048$ \\
\cline { 2 - 3 } & 20-30 kDa chitosan & $2.505 \pm 1.495$ \\
\hline & LMW chitosan & $1.03125 \pm 0.12$ \\
\cline { 2 - 3 } & MMW chitosan & $1.578 \pm 0.453$ \\
\hline
\end{tabular}


A

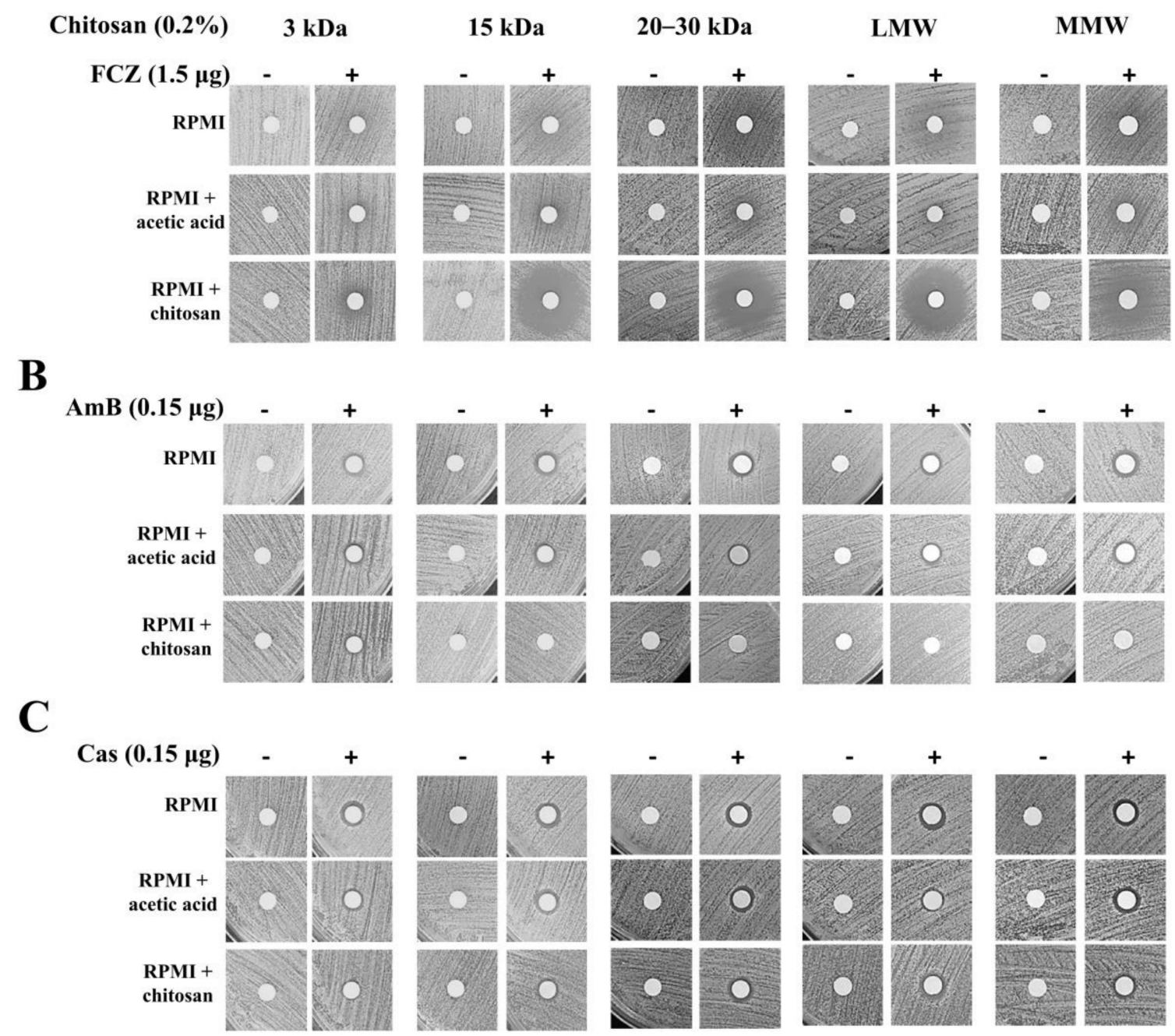

Figure 1. Disk diffusion assay of each chitosan with or without an antifungal drug against C. albicans 5314. (A) Synergistic effects were observed for chitosan in combination with fluconazole (FCZ) against C. albicans SC5314, whereas indifferent effects were observed when chitosan was combined with (B) amphotericin B (AmB) and (C) caspofungin (Cas).

2.3. C. tropicalis MYA3404 Is Highly Susceptible to Chitosan and Chitosan-Fluconazole Treatment Exhibits Synergistic Effects Against C. tropicalis MYA3404

C. tropicalis was selected for this analysis because it is the second most isolated fungal pathogen in Taiwan. The MIC of fluconazole against C. tropicalis MYA3404 was 0.5 (Table 3). Interestingly, except for the $3 \mathrm{kDa}$ chitosan oligomer, each chitosan exhibited a remarkable reduction in MIC (ranging from 1.56-7.81 $\mu \mathrm{g} / \mathrm{mL}$ ) (Table 3) compared with C. albicans SC5314 (Table 1). Checkerboard assays of each chitosan with fluconazole (but not with amphotericin B or caspofungin) were performed because of the indifferent effects of chitosan-amphotericin B and chitosan-caspofungin against C. albicans, as previously observed (Table 2). Similar to the results obtained for C. albicans SC5314, chitosan in combination with fluconazole had a synergistic effect against $C$. tropicalis MYA3404 (FIC index $_{<0.5)}$ (Table 4). Additionally, the disk diffusion assays also indicated that treatment with chitosan-fluconazole exhibited a larger clear zone than treatment with chitosan or fluconazole alone, although $3 \mathrm{kDa}$ and MMW chitosan did not exhibit a clear inhibition zone in the combination treatment (Figure 2). 
Table 3. MICs of chitosans of different MWs and degrees of deacetylation in combination with fluconazole against $C$. tropicalis MYA3404.

\begin{tabular}{ccc}
\hline Chitosan or Drug & Strain & MIC $(\mu \mathrm{g} / \mathbf{m L})$ \\
\hline 3 kDa chitosan & C. tropicalis & 1000 \\
\hline$\sim 15$ kDa chitosan & C. tropicalis & 7.81 \\
\hline $20-30$ kDa chitosan & C. tropicalis & 1.56 \\
\hline LMW chitosan & C. tropicalis & 7.81 \\
\hline MMW chitosan & C. tropicalis & 7.81 \\
\hline Fluconazole & C. tropicalis & 0.5 \\
\hline
\end{tabular}

Table 4. Checkerboard assays of each chitosan in combination with fluconazole against $C$. tropicalis MYA3404.

\begin{tabular}{ccc}
\hline Antifungal Drug & Chitosan & FICindex \\
\hline \multirow{3}{*}{ Fluconazole } & 3 kDa chitosan & $0.375 \pm 0.125$ \\
\cline { 2 - 3 } & $\sim 15$ kDa chitosan & $0.435 \pm 0.165$ \\
\cline { 2 - 3 } & 20-30 kDa chitosan & $0.21 \pm 0.07$ \\
\cline { 2 - 3 } & LMW chitosan & $0.39 \pm 0.11$ \\
\hline & MMW chitosan & $0.42 \pm 0.14$ \\
\hline
\end{tabular}

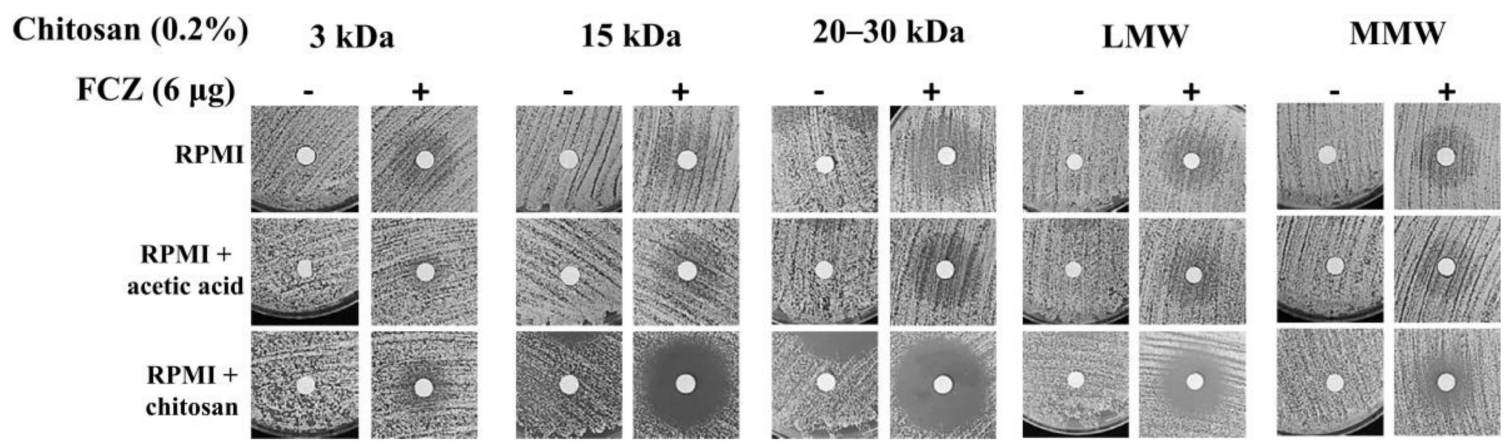

Figure 2. Disk diffusion assay of each chitosan with or without fluconazole against C. tropicalis MYA3404. Different MWs of chitosan (except $3 \mathrm{kDa}$ chitosan) with fluconazole exhibited great cytocidal effects on C. tropicalis MYA3404.

2.4. Combination of Chitosan and Fluconazole Showed Great Fungicidal Activity Against Drug-Resistant C. albicans and C. tropicalis Isolates

To further explore whether the chitosan-fluconazole combination treatment is able to inhibit fluconazole-resistant C. albicans and C. tropicalis isolates, checkerboard assays were performed. First, the MIC values after treatment with fluconazole $(8 \mu \mathrm{g} / \mathrm{mL}$ for $C$. albicans and $512 \mu \mathrm{g} / \mathrm{mL}$ for C. tropicalis isolates) confirmed that these clinical isolates were fluconazole-resistant strains. Nevertheless, combination treatment exhibited a synergistic antifungal effect in both drug-resistant $C$. albicans $\left(\mathrm{FIC}_{\text {index }}<0.5\right)$ and drug-resistant $\mathrm{C}$. tropicalis $\left(\mathrm{FIC}_{\mathrm{index}}<0.5\right)$ and showed an excellent inhibition zone after treatment with chitosan with MWs of $15 \mathrm{kDa}$ and 20-35 kDa and LMW (Table 5 and Figure 3). 
Table 5. Checkerboard assays of each chitosan in combination with fluconazole against fluconazole-resistant clinical strains.

\begin{tabular}{ccc}
\hline Drug-Resistant Strain & Chitosan & FICindex \\
\hline \multirow{3}{*}{ C. albicans } & 3 kDa chitosan & $0.375 \pm 0.125$ \\
\cline { 2 - 3 } & $\sim 15$ kDa chitosan & $0.188 \pm 0.063$ \\
\cline { 2 - 3 } 20-30 kDa chitosan & $0.208 \pm 0.168$ \\
\cline { 2 - 3 } C. tropicalis & LMW chitosan & $0.16 \pm 0.09$ \\
\cline { 2 - 3 } & MMW chitosan & $0.085 \pm 0.015$ \\
\cline { 2 - 3 } & 20-30 kDa chitosan & $0.19 \pm 0.07$ \\
\cline { 2 - 3 } & LMW chitosan & $0.26 \pm 0.24$ \\
\hline
\end{tabular}

A

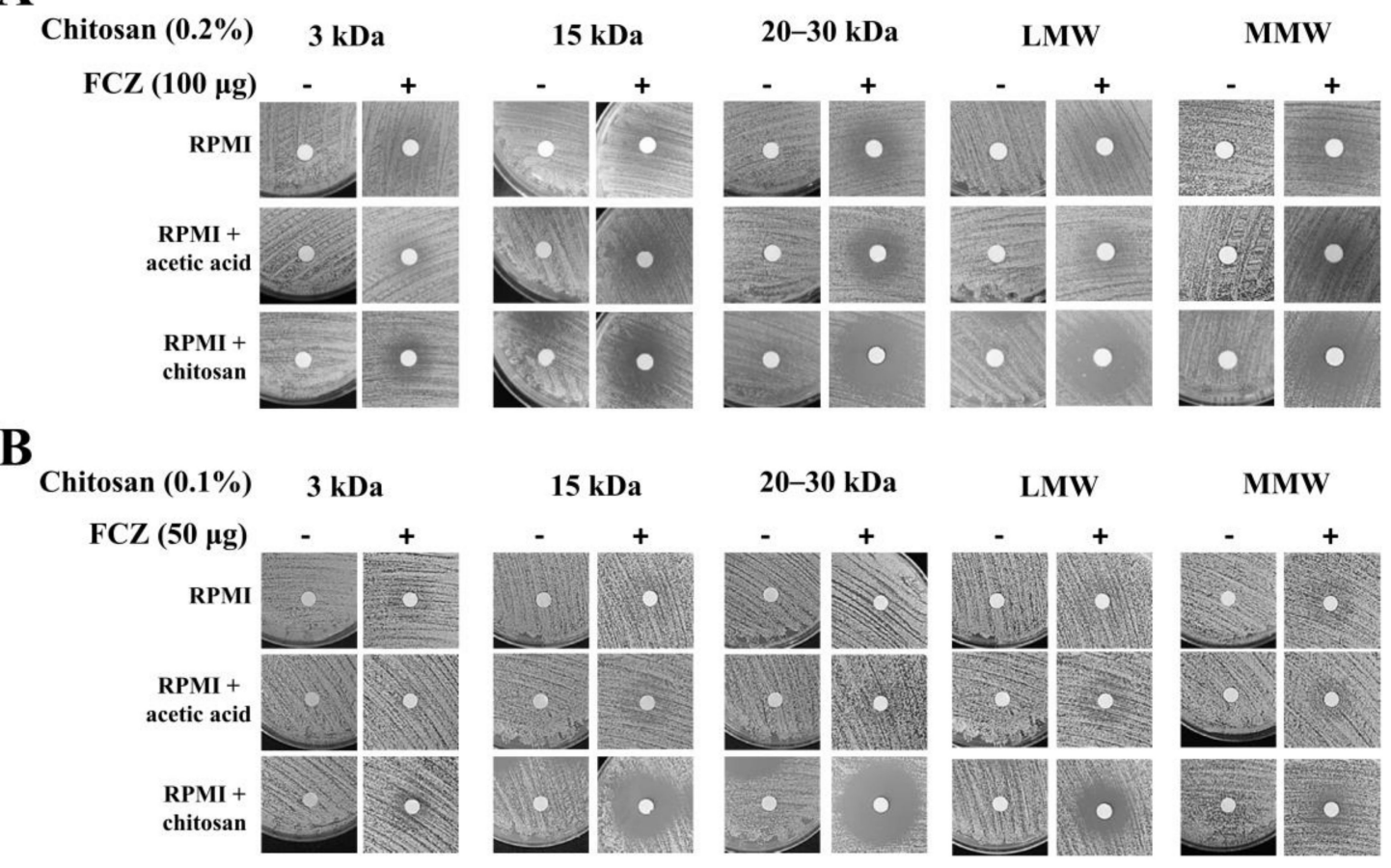

Figure 3. Disk diffusion assay of each chitosan with or without fluconazole against drug-resistant Candida strains. Fluconazole-resistant strains of $C$. albicans and $C$. tropicalis were significantly inhibited after treatment the combination of chitosan and fluconazole, particularly $15 \mathrm{kDa}, 20-35 \mathrm{kDa}$, and LMW chitosan.

\section{Discussion}

The influence of the MW and degree of acetylation of chitosan on antimicrobial activity is diverse and has shown different outcomes [39-41]. In particular, lower deacetylation degrees and MWs of chitosan (between 42.5 and $135 \mathrm{kDa}$ ) exhibited stronger antimicrobial activity against gram-negative bacteria [41]. However, higher MW (300-400 kDa) chitosan and chitosan with a lower degree of deacetylation (but not chitooligosaccharides) had stronger activity against gram-positive bacteria [42]. A similar study indicated that HMW chitosan exhibited better antibacterial activity than chitosan oligomers [39]. These data suggested that the inhibitory effects were also dependent on the pathogen type and chitosan properties as well as the preparation method and chitin source. Indeed, our results 
showed that the chitosan used in this study exhibited different antifungal effects against C. albicans and C. tropicalis. The $3 \mathrm{kDa}$ chitosan oligomers and HMW chitosan exhibited lower antifungal effects against Candida species. Furthermore, $15 \mathrm{kDa}, 20 \mathrm{kDa}$, and LMW chitosan (but not $3 \mathrm{kDa}$ and MMW chitosan) in combination with fluconazole in the checkerboard and disk diffusion assays showed remarkable antifungal effects.

We observed a hundred- to thousand-fold increase in chitosan susceptibility to C. tropicalis compared with C. albicans, thus implying that the cell surface properties of the two Candida species are different. Previous reports have shown that the contents of unsaturated fatty acids positively influence the membrane fluidity [43]. Moreover, the membrane fluidity of filamentous fungi has been reported to contribute to chitosan susceptibility [44]. Higher membrane fluidity tends to result in a more negative charge on the cell membrane $[43,45]$, thus facilitating cationic chitosan binding to the cell membrane. Previous studies have shown that the cell membrane of $C$. tropicalis contains more polyunsaturated fatty acids than that of $C$. albicans, suggesting that the $C$. tropicalis cell membrane has a greater negative charge than the $C$. albicans cell membrane, although the differences are highly dependent on the analytical methods and culture conditions [46-49]. Furthermore, glucan, chitin, and mannan carbohydrates and a few proteins constitute the outer layer of the cell walls of Candida species [50,51]. Mannoproteins (protein-linked mannan) harboring phosphate groups (phosphorylated mannosyl side chains) also confer a negative charge to the fungal cell wall [50-52]. Previous studies have demonstrated that mannan components and the phosphomannan content on the $C$. tropicalis cell wall are significantly higher than those on the C. albicans cell wall [53,54], which might explain why C. tropicalis exhibited remarkably greater chitosan sensitivity than C. albicans.

The mode of action of chitosan against microbes has been investigated and reported in several review articles $[3,4,6-8,22,24,40]$. (1) Chitosan (>50 kDa or higher MW) binds on the microbial cell wall to prevent nutrients from entering the cell, alters the cell permeability, and could act as a metal chelator that inhibits microbial growth [5,6,17,22,55]. Thus, the LMW, MMW, and HMW chitosans used in this study might only target the fungal cell wall. Although the LMW, MMW, or HMW chitosan likely cannot pass through cell wall, because chitosan is a linear polysaccharide, it might be able to penetrate the cell wall and bind to the cell membrane. (2) Chitosan $(<50 \mathrm{kDa}$ or lower molecular weight) might also have intracellular activity, thereby affecting the molecular aspects of DNA, RNA, or protein synthesis. Indeed, reports have demonstrated that chitosan $(\leq 50 \mathrm{kDa})$ and nano-sized particles can penetrate the bacteria cell wall and inhibit DNA transcription [4,56]. Therefore, $3 \mathrm{kDa}$, $15 \mathrm{kDa}$, or 20-30 kDa chitosan may not only present antimicrobial activity when interacting with the cell wall and cell membrane, but also present intracellular antifungal effects. Obviously, the molecular size of chitosan determines its antifungal activity intracellularly or extracellularly. The structure rather than the MW of chitosan also plays crucial roles in the location of antifungal activity.

In this study, three chitosans with specific MWs were applied in combination with fluconazole and caused great synergistic antifungal activity against $C$. albicans and $C$. tropicalis as well as drug-resistant strains with liquid and agar media. However, the combinations of chitosan-amphotericin B and chitosan-caspofungin against $C$. albicans showed indifferent effects. Phospholipids and ergosterol (a targeting site of amphotericin B) are important components of the Candida cell membrane [57]. The $\mathrm{NH}_{3}{ }^{+}$groups of chitosan are believed to be able to bind to negatively charged plasma membranes, thus leading to changes in membrane permeabilization and inhibiting microorganisms $[5-7,23,38,58]$. Amphotericin B consists of mycosamine and macrolactone moieties that can alter the membrane ion permeability and potential on fungal cell membranes [59]. In particular, the mycosamine $\mathrm{NH}_{3}{ }^{+}$of amphotericin B is a critical appendage for the binding to ergosterol [59-61]. Therefore, competitive inhibition likely occurs between chitosan and amphotericin B on the fungal membrane. However, the mechanisms underlying the indifferent effects of the combination of chitosan with caspofungin remain unclear.

C. albicans $(\sim 50 \%)$ and C. tropicalis $(\sim 20 \%)$ are the most frequently isolated Candida species that affect humans in Taiwan $[35,62,63]$. Moreover, C. tropicalis develops fluconazole resistance much more 
rapidly than C. albicans [64]. Indeed, more fluconazole-resistant isolates are observed for C. tropicalis (15\%) than C. albicans (4\%) [65]. However, currently available antifungal drugs are limited and ineffective against new and drug-resistant strains [66,67]. Our findings provide strong evidence that chitosan is a promising alternative for combination therapy against Candida species and drug-resistant strains. The main issue with this treatment is that chitosan exhibits low antimicrobial activity at neutral $\mathrm{pH}$. Thus, the application of chitosan in combination with fluconazole locally for skin and mucosal infections or a chitosan-based nanoparticle as a fluconazole carrier will likely provide more beneficial effects in clinical therapy. Further in vivo animal experiments to validate the in vitro findings are necessary to provide useful guidelines to develop a better method and formulation to manage fungal pathogens.

\section{Materials and Methods}

\subsection{Strains and Media}

The C. albicans and C. tropicalis strains used in this study included the sequence SC5314 strain MYA3404 [33] and clinical isolate [68] obtained from National Taiwan University Hospital. YPD, RPMI 1640 (Roswell Park Memorial Institute 1640) and RPMI 1640 supplemented with chitosan were prepared as previously described [69]. The characteristics of each chitosan used in this study are listed below (Table 6). The $\sim 3 \mathrm{kDa}$ chitosan oligomer (>85\% deacetylation; cat: OC28900) was obtained from Carbosynth Ltd., United Kingdom. The $\sim 15$ kDa chitosan sample (>85\% deacetylation; cat: $21161-50$ ) was purchased from Polysciences, Inc., Warrington, PA, USA. Chitosan (20-30 kDa, >90\% deacetylation) was purchased from Shin Era Technology, Taiwan (cat: CHG-87G). Low-molecular-weight (LMW) chitosan (50-190 kDa; deacetylation 75-85\%; cat: 448869), medium-molecular-weight (MMW) chitosan (deacetylation 75-85\%; cat: 448877), and high-molecular-weight (HMW) chitosan (310-375 kDa; deacetylation $>75 \%$; cat: 419419 ) were purchased from Sigma-Aldrich Co., St. Louis, MO, USA. Chitosan must be dissolved in acetic acid before being added to the medium. The final $\mathrm{pH}$ of each chitosan-containing medium was 6.2 6.3. Moreover, HMW chitosan required a higher acetic acid concentration for dissolution owing to its low solubility, and the final pH of the HMW chitosan medium was 4.5 .

Table 6. Chitosans used in this study. LMW, low molecular weight; MMW, medium MW; HMW, high MW.

\begin{tabular}{ccc}
\hline Chitosan & Molecular Weight & Degree of Deacetylation \\
\hline Chitosan oligomer & $3 \mathrm{kDa}$ & minimum $85 \%$ \\
\hline$\sim 15 \mathrm{kDa}$ chitosan & avg. $15 \mathrm{kDa}$ & minimum $85 \%$ \\
\hline $20-30 \mathrm{kDa}$ chitosan & $20-30 \mathrm{kDa}$ & $\geq 90 \%$ \\
\hline LMW chitosan & $50-190 \mathrm{kDa}$ & $75-85 \%$ \\
\hline MMW chitosan & Not available & $75-85 \%$ \\
\hline HMW chitosan & $310-375 \mathrm{kDa}$ & $>75 \%$ \\
\hline
\end{tabular}

\subsection{MIC and Checkerboard Assays}

The MICs were determined for chitosan, fluconazole, amphotericin B, and caspofungin by broth microdilution $[35,70]$. The MIC was defined as the concentration of the compound that reduces the turbidity of C. albicans and C. tropicalis cells by more than 50\% (fluconazole) or $90 \%$ (chitosan, amphotericin B, and caspofungin) [35,71,72]. A typical synergy checkerboard assay setup was performed using a 96-well plate. Columns 1 to 11 contained twofold serial dilutions of antifungal drug, and rows $A$ to $G$ contained twofold serial dilutions of chitosan. Column 12 contained a serial dilution of antifungal drug alone, and row $\mathrm{H}$ contained a serial dilution of chitosan alone. 
To test the WT C. albicans SC5314 FIC $_{\text {index, }}$ a checkerboard array synergy experiment was performed in which fluconazole in concentrations of $0.0015625-4 \mu \mathrm{g} / \mathrm{mL}$ was combined with $3 \mathrm{kDa}$ chitosan at concentrations of $62.5-4000 \mu \mathrm{g} / \mathrm{mL}, 15 \mathrm{kDa}$ chitosan at concentrations of $62.5-4000 \mu \mathrm{g} / \mathrm{mL}, 20-30 \mathrm{kDa}$ chitosan at concentrations of $62.5-4000 \mu \mathrm{g} / \mathrm{mL}$, LMW chitosan at concentrations of $62.5-4000 \mu \mathrm{g} / \mathrm{mL}$, or MMW chitosan at concentrations of $15.625-1000 \mu \mathrm{g} / \mathrm{mL}$. Amphotericin B $(0.0015625-4 \mu \mathrm{g} / \mathrm{mL})$ and caspofungin $(0.00390625-1 \mu \mathrm{g} / \mathrm{mL})$ in combination with each chitosan were tested. To test the FIC $\mathrm{C}_{\text {index }}$ of the C. albicans drug-resistance strain, fluconazole in concentrations of $1-256 \mu \mathrm{g} / \mathrm{mL}$ was used and combined with each chitosan at the same concentration range.

To test the FIC $_{\text {index }}$ of the WT C. tropicalis MYA3404, a checkerboard array synergy experiment was performed in which fluconazole in concentrations of $0.0625-16 \mu \mathrm{g} / \mathrm{mL}$ was combined with $3 \mathrm{kDa}$ chitosan at concentrations of $62.5-4000 \mu \mathrm{g} / \mathrm{mL}, 15 \mathrm{kDa}$ chitosan at concentrations of $0.15625-10 \mu \mathrm{g} / \mathrm{mL}$, 20-30 kDa chitosan at concentrations of 0.3125-20 $\mu \mathrm{g} / \mathrm{mL}, \mathrm{LMW}$ chitosan at concentrations of $0.15625-10 \mu \mathrm{g} / \mathrm{mL}$, or MMW chitosan at concentrations of $0.0117188-7.5 \mu \mathrm{g} / \mathrm{mL}$. To test the FIC index $_{\text {of }}$ the $C$. tropicalis drug-resistance strain, fluconazole in concentrations of $4-1024 \mu \mathrm{g} / \mathrm{mL}$ was combined with $3 \mathrm{kDa}$ chitosan at concentrations of $62.5-4000 \mu \mathrm{g} / \mathrm{mL}, 15 \mathrm{kDa}$ chitosan at concentrations of 0.9375-60 $\mu \mathrm{g} / \mathrm{mL}, 20-30 \mathrm{kDa}$ chitosan at concentrations of $0.9375-60 \mu \mathrm{g} / \mathrm{mL}$, LMW chitosan at concentrations of $0.9375-60 \mu \mathrm{g} / \mathrm{mL}$, or MMW chitosan at concentrations of $0.15625-10 \mu \mathrm{g} / \mathrm{mL}$.

An antagonist effect was defined as an $\mathrm{FIC}_{\text {index }}$ of $>4$ [73]. MIC and checkerboard assays were performed with three replicates. The formulas (Equations (1), (2), and (3)) for calculating the FIC indices are listed below:

$$
\begin{aligned}
& F I C_{A}=\frac{M I C_{A} \text { combination }}{M I C_{A} \text { alone }} \\
& F I C_{B}=\frac{M I C_{B} \text { combination }}{M I C_{B} \text { alone }} \\
& F I C_{\text {index }}=F I C_{A}+F_{B} C_{B}
\end{aligned}
$$

where $A$ represents chitosan and $B$ represents fluconazole, amphotericin $\mathrm{B}$, or caspofungin.

\subsection{Disk Diffusion Assays}

For the disk diffusion test, $6 \mathrm{~mm}$ disks with different concentrations of fluconazole, amphotericin $\mathrm{B}$, and caspofungin were used according to a previous report with slight modifications [74]. Each disk was placed on the surface of the agar with or without chitosan, the plates were incubated at $37^{\circ} \mathrm{C}$ for $24 \mathrm{~h}$, after which images were taken.

\section{Conclusion}

Fungal infections have become a serious issue over the past decade; however, the limited number of antifungal drugs and the rapid emergence of drug resistance strains might lead to incurable fungal infections. Chitosan has been extensively studied for potential applications in biomedical areas. Our investigation demonstrated that the combination of chitosan with a currently available antifungal drug shows a remarkable synergistic antifungal effect. Thus, the innovative application of chitosan should be explored in the future.

Author Contributions: Conceptualization, W.-H.L., F.-S.D., C.-J.C., and C.-H.L.; methodology, W.-H.L., and F.-S.D.; validation, W.-H.L., and F.-S.D.; formal analysis, W.-H.L., F.-S.D., and C.-H.L.; investigation, W.-H.L., F.-S.D., C.-J.C., and C.-H.L.; resources, C.-H.L.; writing, C.-H.L. C.-H.L. Conceived the study, participated in its design and coordination, and finalized the draft of the manuscript. W.-H.L., and F.-S.D. Contributed equally. All authors have read and agreed to the published version of the manuscript.

Funding: This research was funded by NTU-108L7813 from the National Taiwan University and by MOST-105-2628-B-002-018-MY3 from the Ministry of Science and Technology.

Conflicts of Interest: The authors declare no conflict of interest. 


\section{References}

1. Achkar, J.M.; Fries, B.C. Candida infections of the genitourinary tract. Clin. Microbiol. Rev. 2010, 23, $253-273$. [CrossRef]

2. Kullberg, B.J.; Arendrup, M.C. Invasive candidiasis. N. Engl. J. Med. 2015, 373, 1445-1456. [CrossRef] [PubMed]

3. Azuma, K.; Izumi, R.; Osaki, T.; Ifuku, S.; Morimoto, M.; Saimoto, H.; Minami, S.; Okamoto, Y. Chitin, chitosan, and its derivatives for wound healing: Old and new materials. J. Funct. Biomater. 2015, 6, 104-142, reprinted in J. Funct. Biomater. 2018, 9, 38. [CrossRef] [PubMed]

4. Cheung, R.C.F.; Ng, T.B.; Wong, J.H.; Chan, W.Y. Chitosan: An update on potential biomedical and pharmaceutical applications. Mar. Drugs 2015, 13, 5156-5186. [CrossRef] [PubMed]

5. Hosseinnejad, M.; Jafari, S.M. Evaluation of different factors affecting antimicrobial properties of chitosan. Int. J. Biol. Macromol. 2016, 85, 467-475. [CrossRef] [PubMed]

6. Kong, M.; Chen, X.; Xing, K.; Park, H.J. Antimicrobial properties of chitosan and mode of action: A state of the art review. Int. J. Food Microbiol. 2010, 144, 51-63. [CrossRef]

7. Kumar, M.N.R. A review of chitin and chitosan applications. React. Funct. Polym. 2000, 46, 1-27. [CrossRef]

8. Shahidi, F.; Arachchi, J.K.V.; Jeon, Y.-J. Food applications of chitin and chitosans. Trends Food Sci. Technol. 1999, 10, 37-51. [CrossRef]

9. Schlachet, I.; Halamish, H.M.; Sosnik, A. Mixed Amphiphilic polymeric nanoparticles of chitosan, poly(vinyl alcohol) and poly(methyl methacrylate) for intranasal drug delivery: A preliminary in vivo study. Molecules 2020, 25, 4496. [CrossRef]

10. Loiseau, P.M.; Pomel, S.; Croft, S.L. Chitosan contribution to therapeutic and vaccinal approaches for the control of leishmaniasis. Molecules 2020, 25, 4123. [CrossRef]

11. Lisuzzo, L.; Cavallaro, G.; Milioto, S.; Lazzara, G. Halloysite nanotubes coated by chitosan for the controlled release of khellin. Polymers 2020, 12, 1766. [CrossRef] [PubMed]

12. Bertolino, V.; Cavallaro, G.; Milioto, S.; Lazzara, G. Polysaccharides/halloysite nanotubes for smart bionanocomposite materials. Carbohydr. Polym. 2020, 245, 116502. [CrossRef]

13. Lisuzzo, L.; Cavallaro, G.; Milioto, S.; Lazzara, G. Layered composite based on halloysite and natural polymers: A carrier for the $\mathrm{pH}$ controlled release of drugs. New J. Chem. 2019, 43, 10887-10893. [CrossRef]

14. Alburquenque, C.; Bucarey, S.A.; Cabrera, G.; Urzúa, B.; Hermosilla, G.; Tapia, C.V. Antifungal activity of low molecular weight chitosan against clinical isolates of Candida spp. Med. Mycol. 2010, 48, 1018-1023. [CrossRef]

15. Baker, L.G.; Specht, C.A.; Donlin, M.J.; Lodge, J.K. Chitosan, the deacetylated form of chitin, is necessary for cell wall integrity in Cryptococcus neoformans. Eukaryot. Cell 2007, 6, 855-867. [CrossRef] [PubMed]

16. Hirano, S.; Nagao, N. Effects of chitosan, pectic acid, lysozyme, and chitinase on the growth of several phytopathogens. Agr. Bio. Chem. 1989, 53, 3065-3066.

17. Lim, S.-H.; Hudson, S.M. Review of Chitosan and its derivatives as antimicrobial agents and their uses as textile chemicals. J. Macromol. Sci. Part C 2003, 43, 223-269. [CrossRef]

18. Lin, C.-H.; Chien, H.; Lin, M.-H.; Chen, C.-P.; Shen, M.; Chen, C.-T. Chitosan inhibits the rehabilitation of damaged microbes induced by photodynamic inactivation. Int. J. Mol. Sci. 2018, 19, 2598. [CrossRef]

19. Martínez-Camacho, A.; Cortez-Rocha, M.O.; Ezquerra-Brauer, J.; Graciano-Verdugo, A.; Rodriguez-Félix, F.; Castillo-Ortega, M.; Yépiz-Gómez, M.; Plascencia-Jatomea, M. Chitosan composite films: Thermal, structural, mechanical and antifungal properties. Carbohydr. Polym. 2010, 82, 305-315. [CrossRef]

20. Panwar, R.; Pemmaraju, S.C.; Sharma, A.K.; Pruthi, V. Efficacy of ferulic acid encapsulated chitosan nanoparticles against Candida albicans biofilm. Microb. Pathog. 2016, 95, 21-31. [CrossRef]

21. Peña, A.; Sánchez, N.S.; Calahorra, M. Effects of chitosan on Candida albicans: Conditions for its antifungal activity. BioMed Res. Int. 2013, 2013, 1-15. [CrossRef]

22. Raafat, D.; Von Bargen, K.; Haas, A.; Sahl, H.-G. Insights into the Mode of action of chitosan as an antibacterial compound. Appl. Environ. Microbiol. 2008, 74, 3764-3773. [CrossRef]

23. Rabea, E.I.; Badwy, M.E.-T.; Stevens, C.V.; Smagghe, A.G.; Steurbaut, W. Chitosan as antimicrobial agent: Applications and mode of action. Biomacromolecules 2003, 4, 1457-1465. [CrossRef] [PubMed]

24. Sudarshan, N.R.; Hoover, D.G.; Knorr, D. Antibacterial action of chitosan. Food Biotechnol. 1992, 6, $257-272$. [CrossRef] 
25. Tsai, T.; Chien, H.-F.; Wang, T.-H.; Huang, C.-T.; Ker, Y.-B.; Chen, C. Chitosan augments photodynamic inactivation of gram-positive and gram-negative bacteria. Antimicrob. Agents Chemother. 2011, 55, 1883-1890. [CrossRef]

26. Huang, L.; Dai, T.; Xuan, Y.; Tegos, G.P.; Hamblin, M.R. Synergistic combination of chitosan acetate with nanoparticle silver as a topical antimicrobial: Efficacy against bacterial burn infections. Antimicrob. Agents Chemother. 2011, 55, 3432-3438. [CrossRef]

27. Breser, M.L.; Felipe, V.; Bohl, L.P.; Orellano, M.S.; Isaac, P.; Conesa, A.; Rivero, V.E.; Correa, S.G.; Bianco, I.D.; Porporatto, C. Chitosan and cloxacillin combination improve antibiotic efficacy against different lifestyle of coagulase-negative Staphylococcus isolates from chronic bovine mastitis. Sci. Rep. 2018, 8, 5081. [CrossRef]

28. Yang, K.; Han, Q.; Chen, B.; Zheng, Y.; Zhang, K.; Li, Q.; Wang, J. Antimicrobial hydrogels: Promising materials for medical application. Int. J. Nanomed. 2018, 13, 2217-2263. [CrossRef]

29. Labruère, R.; Sona, A.J.; Turos, E. Anti-methicillin-resistant Staphylococcus aureus nanoantibiotics. Front. Pharmacol. 2019, 10, 1121. [CrossRef]

30. Darwesh, B.; Aldawsari, H.M.; Aburahma, M.H. Optimized chitosan/anion polyelectrolyte complex based inserts for vaginal delivery of fluconazole: In vitro/in vivo evaluation. Pharmaceutics 2018, 10, 227. [CrossRef]

31. Fitaihi, R.A.; Aleanizy, F.S.; Elsamaligy, S.; Mahmoud, H.A.; Bayomi, M.A. Role of chitosan on controlling the characteristics and antifungal activity of bioadhesive fluconazole vaginal tablets. Saudi Pharm. J. 2018, 26, 151-161. [CrossRef]

32. Ganan, M.; Lorentzen, S.B.; Aam, B.B.; Eijsink, V.G.H.; Gaustad, P.; Sørlie, M. Antibiotic saving effect of combination therapy through synergistic interactions between well-characterized chito-oligosaccharides and commercial antifungals against medically relevant yeasts. PLoS ONE 2019, 14, e0227098. [CrossRef]

33. Butler, G.; Rasmussen, M.D.; Lin, M.F.; Santos, M.A.S.; Sakthikumar, S.; Munro, C.A.; Rheinbay, E.; Grabherr, M.; Forche, A.; Reedy, J.L.; et al. Evolution of pathogenicity and sexual reproduction in eight Candida genomes. Nat. Cell Biol. 2009, 459, 657-662. [CrossRef]

34. Falagas, M.E.; Roussos, N.; Vardakas, K.Z. Relative frequency of albicans and the various non-albicans Candida spp among candidemia isolates from inpatients in various parts of the world: A systematic review. Int. J. Infect. Dis. 2010, 14, e954-e966. [CrossRef]

35. Chang, T.-P.; Lo, P.-C.; Wang, A.-H.; Lo, H.-J.; Ho, M.-W.; Yang, Y.-L.; Lin, P.-S. Distribution and drug susceptibilities of Candida species causing candidemia from a medical center in central Taiwan. J. Infect. Chemother. 2013, 19, 1065-1071. [CrossRef] [PubMed]

36. Guinea, J. Global trends in the distribution of Candida species causing candidemia. Clin. Microbiol. Infect. 2014, 20, 5-10. [CrossRef]

37. Nagy, F.; Bozó, A.; Toth, Z.; Daróczi, L.; Majoros, L.; Kovács, R. In vitro antifungal susceptibility patterns of planktonic and sessile Candida kefyr clinical isolates. Med. Mycol. 2017, 56, 493-500. [CrossRef] [PubMed]

38. Sheehan, D.J.; Hitchcock, C.A.; Sibley, C.M. Current and emerging azole antifungal agents. Clin. Microbiol. Rev. 1999, 12, 40-79. [CrossRef]

39. No, H.K.; Park, N.Y.; Lee, S.H.; Meyers, S.P. Antibacterial activity of chitosans and chitosan oligomers with different molecular weights. Int. J. Food Microbiol. 2002, 74, 65-72. [CrossRef]

40. Mellegård, H.; Strand, S.; Christensen, B.; Granum, P.E.; Hardy, S.P. Antibacterial activity of chemically defined chitosans: Influence of molecular weight, degree of acetylation and test organism. Int. J. Food Microbiol. 2011, 148, 48-54. [CrossRef] [PubMed]

41. Younes, I.; Sellimi, S.; Rinaudo, M.; Jellouli, K.; Nasri, M. Influence of acetylation degree and molecular weight of homogeneous chitosans on antibacterial and antifungal activities. Int. J. Food Microbiol. 2014, 185, 57-63. [CrossRef]

42. Omura, Y.; Shigemoto, M.; Akiyama, T.; Saimoto, H.; Shigemasa, Y.; Nakamura, I.; Tsuchido, T. Antimicrobial activity of chitosan with different degrees of acetylation and molecular weights. Biocontrol Sci. 2003, 8, 25-30. [CrossRef]

43. Davey, J. Bringing it all together. Nat. Cell Biol. 1989, 339, 591. [CrossRef]

44. Palma-Guerrero, J.; Lopez-Jimenez, J.A.; Pérez-Berná, A.J.; Huang, I.-C.; Jansson, H.-B.; Salinas, J.; Villalaín, J.; Read, N.D.; Lopez-Llorca, L.V. Membrane fluidity determines sensitivity of filamentous fungi to chitosan. Mol. Microbiol. 2010, 75, 1021-1032. [CrossRef] 
45. Kumariya, R.; Sood, S.K.; Rajput, Y.S.; Saini, N.; Garsa, A.K. Increased membrane surface positive charge and altered membrane fluidity leads to cationic antimicrobial peptide resistance in Enterococcus faecalis. Biochim. Biophys. Acta Biomembr. 2015, 1848, 1367-1375. [CrossRef]

46. Schneider, H.; Fuhrmann, G.F.; Fiechter, A. Plasma membrane from Candida tropicalis grown on glucose or hexadecane. II. Biochemical properties and substrate-induced alterations. Biochim. Biophys. Acta Biomembr. 1979, 554, 309-322. [CrossRef]

47. Yano, K.; Yamada, T.; Banno, Y.; Sekiya, T.; Nozawa, Y. Modification of lipid composition in a dimorphic fungus, Candida albicans during the yeast cell to hypha transformation. Jpn. J. Med. Mycol. 1982, 23, 159-165. [CrossRef]

48. Ghannoum, M.A.; Janini, G.; Khamis, L.; Radwan, S.S. Dimorphism-associated variations in the lipid composition of Candida albicans. Microbiology 1986, 132, 2367-2375. [CrossRef] [PubMed]

49. Tylicki, A.; Siemieniuk, M.; Dobrzyn, P.; Ziolkowska, G.; Nowik, M.; Czyzewska, U.; Pyrkowska, A. Fatty acid profile and influence of oxythiamine on fatty acid content in Malassezia pachydermatis, Candida albicans and Saccharomyces cerevisiae. Mycoses 2011, 55, e106-e113. [CrossRef]

50. Chaffin, W.L. Candida albicans cell wall proteins. Microbiol. Mol. Biol. Rev. 2008, 72, 495-544. [CrossRef] [PubMed]

51. Gow, N.A.R.; Latge, J.-P.; Munro, C.A. The fungal cell wall: Structure, biosynthesis, and function. The Fungal Kingdom 2017, 5, 267-292. [CrossRef]

52. Hall, R.A.; Gow, N.A.R. Mannosylation in Candida albicans: Role in cell wall function and immune recognition. Mol. Microbiol. 2013, 90, 1147-1161. [CrossRef]

53. Walker, L.A.; Munro, C.A. Caspofungin induced cell wall changes of Candida species influences macrophage interactions. Front. Cell. Infect. Microbiol. 2020, 10, 164. [CrossRef]

54. Navarro-Arias, M.J.; Hernández-Chávez, M.J.; Garcia-Carnero, L.C.; Amezcua-Hernández, D.G.; E Lozoya-Pérez, N.; Estrada-Mata, E.; Martínez-Duncker, I.; Franco, B.; Mora-Montes, H.M. Differential recognition of Candida tropicalis, Candida guilliermondii, Candida krusei, and Candida auris by human innate immune cells. Infect. Drug Resist. 2019, 12, 783-794. [CrossRef] [PubMed]

55. Verlee, A.; Mincke, S.; Stevens, C.V. Recent developments in antibacterial and antifungal chitosan and its derivatives. Carbohydr. Polym. 2017, 164, 268-283. [CrossRef]

56. Kravanja, G.; Primožič, M.; Knez, Ž.; Leitgeb, M. Chitosan-based (nano)materials for novel biomedical applications. Molecules 2019, 24, 1960. [CrossRef]

57. Noor, A.; Preuss, C.V. Amphotericin B. In Stat Pearls; Publishing Treasure: Island, FL, USA, 2020.

58. Zakrzewska, A.; Boorsma, A.; Brul, S.; Hellingwerf, K.J.; Klis, F.M. Transcriptional response of Saccharomyces cerevisiae to the plasma membrane-perturbing compound chitosan. Eukaryot. Cell 2005, 4, 703-715. [CrossRef]

59. Matsumori, N.; Sawada, Y.; Murata, M. Mycosamine orientation of amphotericin B controlling interaction with ergosterol: Sterol-dependent activity of conformation-restricted derivatives with an amino-carbonyl bridge. J. Am. Chem. Soc. 2005, 127, 10667-10675. [CrossRef]

60. Gray, K.C.; Palacios, D.S.; Dailey, I.; Endo, M.M.; Uno, B.E.; Wilcock, B.C.; Burke, M.D. Amphotericin primarily kills yeast by simply binding ergosterol. Proc. Natl. Acad. Sci. USA 2012, 109, 2234-2239. [CrossRef]

61. Palacios, D.S.; Dailey, I.; Siebert, D.M.; Wilcock, B.C.; Burke, M.D. Synthesis-enabled functional group deletions reveal key underpinnings of amphotericin B ion channel and antifungal activities. Proc. Natl. Acad. Sci. 2011, 108, 6733-6738. [CrossRef] [PubMed]

62. Chen, P.-Y.; Chuang, Y.-C.; Wang, J.-T.; Sheng, W.-H.; Yu, C.-J.; Chu, C.-C.; Hsueh, P.-R.; Chen, Y.-C.; Chen, Y.-C. Comparison of epidemiology and treatment outcome of patients with candidemia at a teaching hospital in Northern Taiwan, in 2002 and 2010. J. Microbiol. Immunol. Infect. 2014, 47, 95-103. [CrossRef] [PubMed]

63. Chuang, Y.-C.; Chen, Y.-C.; Chen, Y.-C.; Sun, C.-C.; Chang, Y.-Y.; Chen, M.-L.; Hsu, L.-Y.; Wang, J.-L. Secular trends of healthcare-associated infections at a teaching hospital in Taiwan, 1981-2007. J. Hosp. Infect. 2010, 76, 143-149. [CrossRef]

64. Barchiesi, F.; Calabrese, D.; Sanglard, D.; Di Francesco, L.F.; Caselli, F.; Giannini, D.; Giacometti, A.; Gavaudan, S.; Scalise, G. Experimental induction of fluconazole resistance in Candida tropicalis ATCC 750. Antimicrob. Agents Chemother. 2000, 44, 1578-1584. [CrossRef] [PubMed] 
65. Yang, Y.-L.; Ho, Y.-A.; Cheng, H.-H.; Ho, M.; Lo, H.-J. Susceptibilities of Candida species to amphotericin B and fluconazole: The emergence of fluconazole resistance in Candida tropicalis. Infect. Control. Hosp. Epidemiol. 2004, 25, 60-64. [CrossRef]

66. Ford, C.B.; Funt, J.M.; Abbey, D.; Issi, L.; Guiducci, C.; A Martinez, D.; DeLorey, T.; Li, B.Y.; White, T.C.; Cuomo, C.A.; et al. The evolution of drug resistance in clinical isolates of Candida albicans. eLife 2015, 4, e00662. [CrossRef]

67. McManus, B.A.; Coleman, D.C. Molecular epidemiology, phylogeny and evolution of Candida albicans. Infect. Genet. Evol. 2014, 21, 166-178. [CrossRef] [PubMed]

68. Chien, H.-F.; Chen, C.-P.; Chen, Y.-C.; Chang, P.-H.; Tsai, T.; Chen, C. The use of chitosan to enhance photodynamic inactivation against Candida albicans and its drug-resistant clinical isolates. Int. J. Mol. Sci. 2013, 14, 7445-7456. [CrossRef]

69. Shih, P.-Y.; Liao, Y.-T.; Tseng, Y.-K.; Deng, F.-S.; Lin, C.-H. A potential antifungal effect of chitosan against Candida albicans is mediated via the inhibition of SAGA complex component expression and the subsequent alteration of cell surface integrity. Front. Microbiol. 2019, 10, 602. [CrossRef]

70. Clinical Laboratory Standard Institute. Reference Method for Broth Dilution Antifungal Susceptibility Testing of Yeasts; Approved Standard-Third Edition; CLSI document M27-A3; Clinical Laboratory Standard Institute: Wayne, PA, USA, 2008.

71. Ing, L.Y.; Zin, N.M.; Sarwar, A.; Katas, H. Antifungal activity of chitosan nanoparticles and correlation with their physical properties. Int. J. Biomater. 2012, 2012, 1-9. [CrossRef]

72. Ahmed, F.; Soliman, F.M.; Adly, M.A.; Soliman, H.A.; El-Matbouli, M.; Saleh, M. In vitro assessment of the antimicrobial efficacy of chitosan nanoparticles against major fish pathogens and their cytotoxicity to fish cell lines. J. Fish Dis. 2020, 43, 1049-1063. [CrossRef]

73. White, R.L.; Burgess, D.S.; Manduru, M.; A Bosso, J. Comparison of three different in vitro methods of detecting synergy: Time-kill, checkerboard, and E test. Antimicrob. Agents Chemother. 1996, 40, 1914-1918. [CrossRef]

74. Bonev, B.; Hooper, J.; Parisot, J. Principles of assessing bacterial susceptibility to antibiotics using the agar diffusion method. J. Antimicrob. Chemother. 2008, 61, 1295-1301. [CrossRef] [PubMed]

Sample Availability: Samples of the compounds are not available from the authors.

Publisher's Note: MDPI stays neutral with regard to jurisdictional claims in published maps and institutional affiliations. 